\title{
Chemical cleaning of RO membranes fouled by wastewater effluent: Achieving higher efficiency with dual-step cleaning
}

\author{
Wui Seng Ang ${ }^{1}$, Ngai Yin Yip, Alberto Tiraferri, Menachem Elimelech* \\ Department of Chemical and Environmental Engineering, Yale University, New Haven, CT 06520-8286, United States
}

\section{A R T I C L E I N F O}

\section{Article history:}

Received 10 June 2011

Received in revised form 29 July 2011

Accepted 31 July 2011

Available online 4 August 2011

\section{Keywords:}

Reverse osmosis

Chemical cleaning

Fouling

Wastewater effluent

Cleaning efficiency

Organic fouling

Effluent organic matter

Wastewater reclamation

Membranes

\begin{abstract}
A B S T R A C T
The effect of different modes of cleaning of RO membranes fouled by wastewater treatment plant effluent has been investigated. Characterization of the wastewater effluent revealed the presence of foulants containing carboxylic and phenolic functional groups as well as calcium ions. The chemical cleaning agents, sodium hydroxide $(\mathrm{NaOH})$, ethylenediaminetetraacetic acid (EDTA), sodium dodecyl sulfate (SDS), and sodium chloride $(\mathrm{NaCl})$, were selected as models for alkaline solutions, metal chelating agents, surfactants, and salt cleaning, respectively. Specifically, we examined the impact of a sequence or a combination of two cleaning agents compared to the use of single cleaning agents. Increased cleaning efficiency was demonstrated when two cleaning agents were applied in a certain order and mixture. In particular, it was shown that addition of $\mathrm{NaOH}$ can enhance the overall cleaning performance when introduced with other chemical agents, due to its ability to loosen the fouling layer. Cleaning efficiency as high as $94 \%$ was obtained by simply increasing the $\mathrm{pH}$ of an $\mathrm{NaCl}$ cleaning solution, compared to $65 \%$ in the case of the individual salt solution with no $\mathrm{pH}$ adjustment. On the other hand, combining chemical cleaning agents was not advantageous in some cases, possibly because of the competing cleaning mechanisms of some of the agents. The most and the least effective cleaning modes were highlighted, suggesting a rationale for the design of chemical cleaning of RO membranes fouled by wastewater effluent. This study demonstrates that careful selection of cleaning agents and the steps through which those agents are applied allows the regeneration of high water productivity after fouling while minimizing both the cleaning time and the amount of chemicals.
\end{abstract}

(c) 2011 Elsevier B.V. All rights reserved.

\section{Introduction}

The increase in global demand for potable water exerts considerable strain on the supply from conventional freshwater sources, such as rivers and lakes. Thus, alternative solutions that extract clean water from less conventional sources, such as the treatment of secondary wastewater effluent in advanced wastewater reclamation for indirect potable use [1,2], are gaining popularity. However, the use of membrane technology in advanced wastewater reclamation is impeded by the phenomenon of fouling. Secondary treated effluent from wastewater treatment plants contains dissolved organic matter, commonly known as effluent organic matter (EfOM), which contributes to organic fouling [1]. EfOM comprises polysaccharides, proteins, amino sugars, nucleic acids, humic and fulvic acids, organic acids, and cell components [1].

\footnotetext{
* Corresponding author. Tel.: +1 203432 2789; fax: +1 2034324387 .

E-mail address: menachem.elimelech@yale.edu (M. Elimelech).

1 Current address: Public Utility Board of Singapore, Singapore.
}

Since EfOM is generally smaller than the pore size of an ultrafiltration (UF) membrane, it can readily pass through the microfiltration (MF) or UF membrane typically employed in the pretreatment step of an advanced wastewater reclamation plant. The EfOM, which passes through the pretreatment process, causes fouling of the reverse osmosis (RO) membrane in the subsequent RO filtration step. Furthermore, the ubiquitous calcium cation $\left(\mathrm{Ca}^{2+}\right)$ present in wastewater effluents contributes significantly to RO membrane fouling by forming complexes with the constituents of EfOM, such as polysaccharides [2] and natural organic matter [3]. Fouling of the membrane results in productivity decline, deteriorated permeate quality, increased energy consumption, increased treatment cost, and shortened membrane lifespan [4]. Periodic cleaning of the membrane is therefore required to restore this loss in membrane performance.

Chemical cleaning agents are commonly used to remove the foulant deposited on membrane surfaces [5-10]. Typical chemicals used for membrane cleaning include alkaline solutions, metal chelating agents, surfactants, and salt solutions $[8,11,12]$. Alkaline solutions clean organic-fouled membranes by hydrolysis and solubilization, and by generating electrostatic interactions between the 
negatively charged foulants and membranes when the solution $\mathrm{pH}$ is elevated [13]. Metal chelating agents break down the structural integrity of the fouling layer by removing divalent cations in the fouling layer, which serve as binding agents for organic molecules [3]. Surfactants are compounds that have both hydrophilic and hydrophobic groups, and are semi-soluble in both organic and aqueous solvents. Surfactants can solubilize macromolecules by forming micelles around them [14], and help to clean the surface of the fouled membrane. Sodium chloride $(\mathrm{NaCl})$ and other common inert salts can be used as an effective alternative for the cleaning of RO membranes fouled by gel-forming hydrophilic organic foulants [15]. The proposed cleaning mechanisms involve swelling of the fouling layer in the presence of a salt solution and ion-exchange reaction of $\mathrm{Na}^{+}$with the polysaccharide-calcium complex in the fouling layer.

Optimizing the use of cleaning agents is necessary to maximize cost-efficiency of the process and minimize the use of harmful chemicals. Underdosing of chemical agents will result in ineffective foulant removal and hence, achieve inadequate performance recovery. On the other hand, overdosing can have unintended detrimental effects on the membrane selective layer. For example, excess alkalinity in the cleaning agent can raise the solution $\mathrm{pH}$ beyond the membrane manufacturer's recommended exposure range, resulting in compromised selectivity [16]. The additional cost of superfluous chemicals as a result of overdosing can be significant. Furthermore, the discharge of chemicals into the environment can have deleterious effects. For instance, the discharge of ethylenediaminetetraacetic acid (EDTA), which is non-biodegradable, into receiving waters and the environment can remobilize toxic heavy metal ions from soil [17] and adversely affect contaminant transport.

Previous research on chemical cleaning of RO membranes has mostly focused on laboratory-prepared solutions containing mixtures of organic foulants to simulate wastewater effluent $[11,18]$. In this study, we investigate the chemical cleaning of RO membranes fouled by wastewater effluent collected at a municipal wastewater treatment plant. The chemical cleaning agents, sodium hydroxide $(\mathrm{NaOH})$, EDTA, sodium dodecyl sulfate (SDS), and $\mathrm{NaCl}$, were selected as models for alkaline solutions, metal chelating agents, surfactants, and salt cleaning, respectively. The fouled membranes were cleaned using: individual cleaning agents, various combinations of cleaning agents, and pairs of cleaning agents, administered in different sequences, to investigate the effects of different applications of cleaning agents on performance recovery. The results demonstrate enhanced cleaning effects when cleaning agents are used in a certain order during dual cleaning, as compared to cleaning with individual cleaning agents for the same duration of cleaning time.

\section{Materials and methods}

\subsection{Wastewater effluent characterization}

Wastewater effluent was collected at a municipal treatment plant located in Wallingford, Connecticut, USA. The effect of the presence of bacteria in the effluent was minimized by collecting the wastewater effluent after the UV disinfection stage at the treatment plant and by keeping the effluent in storage under refrigeration at $4{ }^{\circ} \mathrm{C}$. Key properties of the secondary wastewater effluent are shown in Table 1 . The parameters are analyzed based on 12-18 samples from 3 batches of wastewater effluent that were collected at the treatment plant every few weeks, with the exception of fatty acid analysis, which is based on 2 samples. The presented solution $\mathrm{pH}$ is the average of the solution $\mathrm{pH}$ taken at the start of the fouling experiment. The BOD data was obtained from the plant's laboratory. The cations and anions were analyzed using ion chromatography.
Table 1

Wastewater effluent characteristic parameters.

\begin{tabular}{|c|c|}
\hline Parameter & Value \\
\hline $\mathrm{pH}$ & $6.1-6.8$ \\
\hline BOD & $3-5 \mathrm{mg} / \mathrm{L}$ \\
\hline TOC & $6-10 \mathrm{mg} / \mathrm{L}$ \\
\hline $\mathrm{Ca}^{2+}$ & $0.52 \pm 0.03 \mathrm{mM}$ \\
\hline $\mathrm{Na}^{+}$ & $1.87 \pm 0.12 \mathrm{mM}$ \\
\hline $\mathrm{Mg}^{2+}$ & $0.23 \pm 0.03 \mathrm{mM}$ \\
\hline $\mathrm{K}^{+}$ & $0.21 \pm 0.02 \mathrm{mM}$ \\
\hline $\mathrm{Cl}^{-}$ & $1.72 \pm 0.33 \mathrm{mM}$ \\
\hline $\mathrm{NO}_{3}^{-}$ & $0.37 \pm 0.13 \mathrm{mM}$ \\
\hline $\mathrm{PO}_{4}^{3-}$ & $0.08 \pm 0.02 \mathrm{mM}$ \\
\hline $\mathrm{SO}_{4}{ }^{3-}$ & $0.04 \pm 0.01 \mathrm{mM}$ \\
\hline Polysaccharides (as alginate) & $32.9 \pm 6.3 \mathrm{mg} / \mathrm{L}$ \\
\hline Proteins (as BSA) & $9.9 \pm 2.5 \mathrm{mg} / \mathrm{L}$ \\
\hline NOM (as SRNOM) & $25.3 \pm 1.5 \mathrm{mg} / \mathrm{L}$ \\
\hline Fatty acids $\left(\mathrm{C}_{11}-\mathrm{C}_{24}\right)$ & $329.8 \pm 1.6 \mu \mathrm{g} / \mathrm{L}$ \\
\hline
\end{tabular}

The polysaccharide, protein, NOM, and fatty acid concentrations were analyzed, respectively, by the Dubois colorimetric method [19], the modified Lowry method [20], ultraviolet-visible (UV-vis) spectroscopy [21], and electrospray ionization tandem mass spectrometry [22]. (Analysis was carried out by the Kansas Lipidomics Research Center, Kansas State University.)

The data suggest that the wastewater effluent was close to neutral $\mathrm{pH}$ range and had relatively low organic content. The average $\mathrm{Ca}^{2+}$ concentration was similar to that of the feed solution $(0.5 \mathrm{mM})$ in previous fouling experiments with organic foulants, and the approximate ionic strength was slightly less than half that of the feed solution (10 mM) [11,23,24]. Among the various foulant types, polysaccharides (using alginate as a reference polysaccharide) were the most abundant. The measurements of the various foulant types were not mutually exclusive; for example, some natural organic matter can contain protein-based substances.

\subsection{Chemical cleaning agents}

The chemical cleaning agents used were $\mathrm{NaOH}(\mathrm{pH} 11.0)$ as an alkaline solution, certified grade disodium ethylenediaminetetraacetate $\left(\mathrm{Na}_{2}\right.$-EDTA) as a metal chelating agent, certified grade sodium dodecyl sulfate (SDS) as an anionic surfactant, and $\mathrm{NaCl}$ as a salt cleaning solution. The agents were purchased from Fisher Scientific (Pittsburgh, PA) and used without further purification. The stock chemical solutions were freshly prepared by dissolving each chemical in deionized (DI) water. The pH of the EDTA, SDS, and $\mathrm{NaCl}$ cleaning solutions was adjusted with $1.0 \mathrm{M} \mathrm{NaOH}$ as necessary.

\subsection{RO membrane and test unit}

The relatively well-characterized thin-film composite LFC-1 membrane (Hydranautics, Oceanside, CA) was used as a model RO membrane. The average hydraulic permeability was determined to be $3.92 \pm 0.47 \mathrm{~L} \mathrm{~m}^{-2} \mathrm{~h}^{-1}$ bar $^{-1}\left(1.09 \pm 0.13 \times 10^{-11} \mathrm{~m} \mathrm{~s}^{-1} \mathrm{~Pa}^{-1}\right)$. The observed salt rejection was $98.7-99.3 \%$, as determined using a $10 \mathrm{mM}(584 \mathrm{mg} / \mathrm{L}) \mathrm{NaCl}$ feed solution at an applied pressure of $20.68 \mathrm{bar}(300 \mathrm{psi}$ ) and a crossflow velocity of $8.1 \mathrm{~cm} / \mathrm{s}$. Membrane samples were received as dry flat sheets, and were cut and stored in DI water at $4{ }^{\circ} \mathrm{C}$. The membrane has been reported to be negatively charged at solution chemistries typical to natural and waste waters, with an isoelectric point of about $\mathrm{pH} 4$ [25]. It has been suggested that the membrane is coated with a neutral polyalcohol layer rich in - $\mathrm{COH}$ functional groups, which make the surface less charged than the surfaces of other polyamide RO membranes without a coating layer [26].

Fouling of the membranes and the ensuing cleaning experiments were performed with a laboratory-scale cross-flow test unit, 
following the procedure described in our previous publication [11]. The membrane test unit comprised a membrane cell, pump, feed reservoir, temperature control system, and data acquisition system. The membrane cell is a rectangular plate-and-frame unit, containing a flat membrane sheet placed in a rectangular channel with dimensions measuring $7.7 \mathrm{~cm}$ long, $2.6 \mathrm{~cm}$ wide, and $0.3 \mathrm{~cm}$ high. Feed spacers were not employed, and the feed solution was circulated in crossflow along the length of the membrane channel. Both permeate and retentate were recirculated back to the feed reservoir. Permeate flux was registered continuously by a digital flow meter (Optiflow 1000, Humonics, Inc., Folsom, CA), interfaced with a computer. A floating disc rotameter (King Instrument Company, Garden Grove, CA) was used to monitor the retentate flow rate. The crossflow velocity and the operating pressure were adjusted using a bypass valve (Swagelok, Solon, $\mathrm{OH}$ ) in conjunction with a back-pressure regulator (U.S. Para Plate, Auburn, CA). Temperature was controlled by a recirculating chiller/heater (Model 633, Polysciences) with a stainless steel coil submerged in the feed water reservoir.

\subsection{Fouling and cleaning experiments}

The membrane was first compacted with DI water until the permeate flux became constant, followed by the initial baseline performance for $1 \mathrm{~h}$. The flux at which the baseline run was performed was pre-determined so that the initial flux at the onset of fouling dropped to a specified flux of $83 \mathrm{~L} \mathrm{~m}^{-2} \mathrm{~h}^{-1}\left(2.3 \times 10^{-5} \mathrm{~m} / \mathrm{s}\right)$ after decanting the DI water and adding the wastewater effluent to the feed reservoir. The pump was momentarily stopped to decant the DI water. It was restarted after adding the wastewater effluent and operated at the same applied hydraulic pressure used to obtain the baseline. To prepare the feed solution for fouling experiments, the wastewater effluent was carefully poured out of the storage containers to prevent settled particles from being stirred up. The wastewater effluent was then filtered with a $38-\mu \mathrm{m}$ sieve to remove particles in the feed, but was not pretreated with a filter possessing a pore size typical to that of an MF membrane, in order to maintain accelerated fouling conditions. Fouling runs were carried out for $17 \mathrm{~h}$. At the end of fouling, the solution in the feed reservoir was discarded and cleaning of the fouled membrane was performed by adding the chemical cleaning solution to the feed reservoir. At the end of the cleaning stage, the chemical cleaning solution in the reservoir was emptied, and the reservoir and membrane cell were rinsed with DI water to flush out the residual chemical cleaning solution. Finally, the cleaned RO membrane was subjected to the second baseline performance with DI water to determine the pure water flux.

The crossflow velocity throughout the experiment, except during cleaning, was maintained at $8.6 \mathrm{~cm} / \mathrm{s}$. The operating conditions (i.e., initial flux, crossflow velocity, and temperature) at this stage were identical to those applied during the initial baseline performance, so as to determine the cleaning efficiency, defined as the ratio between the pure water fluxes determined after cleaning and before fouling. Throughout all of the fouling/cleaning stages, the wastewater effluent in the reservoir located on top of a magnetic stirrer was mixed vigorously to ensure complete mixing of the wastewater effluent.

\section{Results and discussion}

\subsection{Wastewater characteristics}

Membrane fouling is influenced by the electrostatic interactions between the organic foulants and the membrane surface, (which affect foulant deposition during initial fouling), and among organic

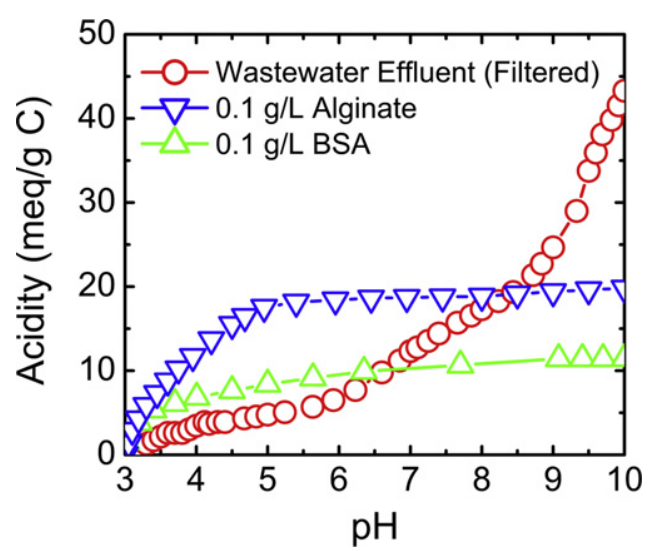

Fig. 1. Acidity of wastewater effluent as a function of $\mathrm{pH}$, as compared to that of alginate and BSA. The wastewater effluent was filtered through a $0.45-\mu \mathrm{m}$ filter. The concentrations of alginate and BSA solutions are each $0.1 \mathrm{~g} / \mathrm{L}$, with a background electrolyte solution of $10 \mathrm{mM} \mathrm{NaCl}$. Potentiometric titration was performed from $\mathrm{pH}$ 3.0 to 10.0 using $0.10 \mathrm{M} \mathrm{NaOH}$ in a carbonate-free $\mathrm{N}_{2}$ atmosphere at $23 \pm 0.5^{\circ} \mathrm{C}$. Blank tests were performed with foulant-free electrolyte solution prior to each sample titration.

foulants, (which affect intermolecular adhesion and subsequent foulant deposition on the fouled membrane). To gain insight into the charge characteristics of the wastewater effluent, the acidity of wastewater effluent was determined by potentiometric titration from $\mathrm{pH} 3.0$ to $\mathrm{pH} 10.0$ (Fig. 1). The acidity profiles of alginate and BSA are also included for comparison purposes.

The increase in acidity of the wastewater effluent from $\mathrm{pH} 3.0$ to 8.0 is attributed to the deprotonation of the carboxylic functional groups [27]. The increase in acidity from pH 8.0 to 10.0 was relatively more significant, and is attributed to the presence of phenolic functional groups [27]. Thus, unlike specific organic foulants, such as alginate or BSA, the wastewater effluent is made up of a complex mixture of organic foulants with varying charge characteristics. Nonetheless, the charged functional groups of the wastewater effluent in the $\mathrm{pH}$ range indicated in Table 1 are predominantly the carboxylic moieties.

\subsection{Fouling behavior with wastewater effluent}

A typical profile of the permeate flux with time is shown in Fig. 2, together with representative SEM images of the virgin membranes (before fouling run), membranes that had been fouled by wastewater effluent (at the end the fouling run), and fouled membranes subsequently cleaned with $2 \mathrm{mM}$ EDTA (after chemical cleaning). The SEM image of the virgin membrane indicates a pristine polyamide active layer that is free of foulants. The initial flux data $(0-1 \mathrm{~h})$ represent the permeate flux of the virgin membrane with DI water. After an hour of baseline run, the pump was stopped and DI water was decanted. After adding wastewater effluent to the feed reservoir (Step 1), the pump was restarted. The permeate flux dropped immediately due to the immediate impact of the feed osmotic pressure. During the fouling stage, the flux decreased almost constantly with time until the fouling run ended after $17 \mathrm{~h}$. The SEM image of the fouled membrane shows a complete coverage of the active layer by deposited foulants. Cleaning of the fouled membrane was performed by adding the cleaning agent solution to the feed reservoir (Step 2). At the end of the cleaning time (15 min), the cleaning agent solution in the feed reservoir was emptied. To determine the efficiency of the cleaning agent, the RO membrane was subjected to a second baseline run by filling the reservoir with DI water and running it at the same operating pressure as that in the earlier baseline run (Step 3). Cleaning efficiency is defined as the ratio of the DI water flux after Step 3 to the initial DI water 


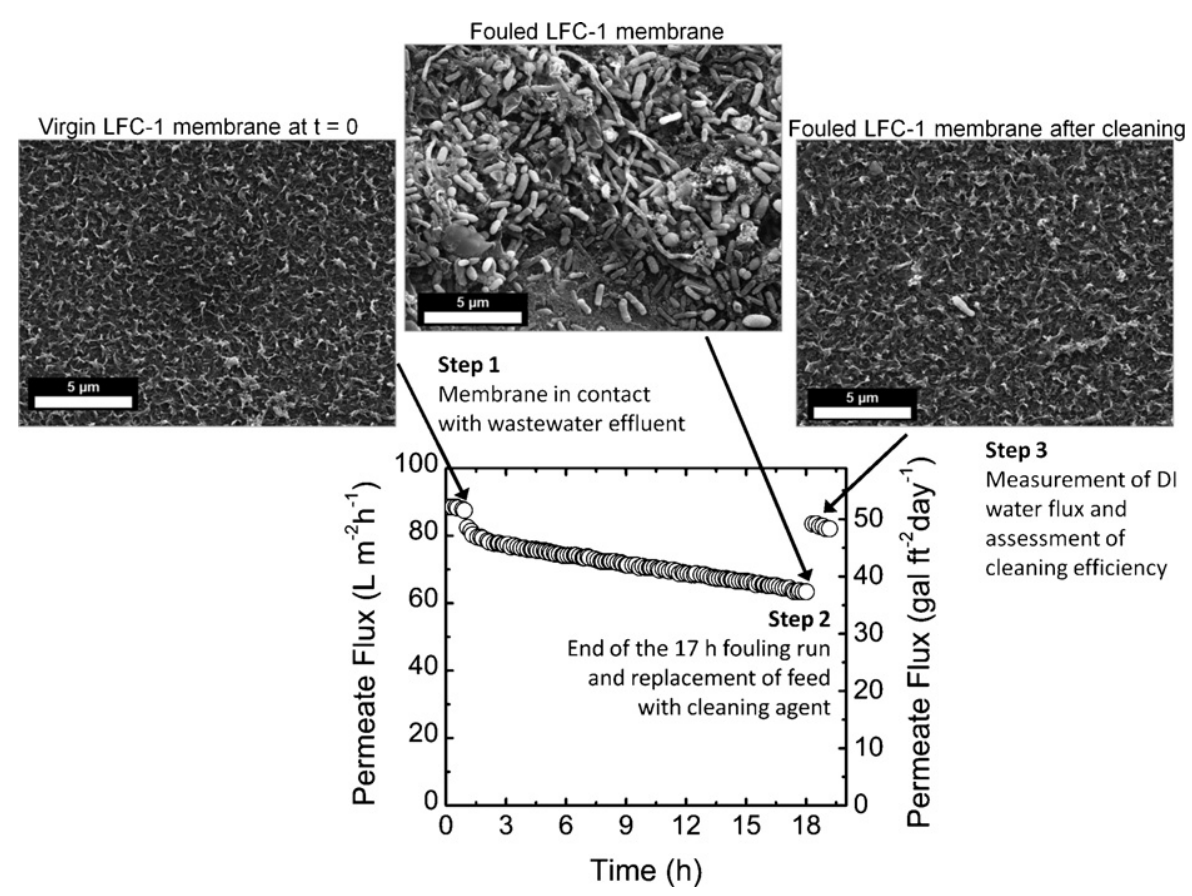

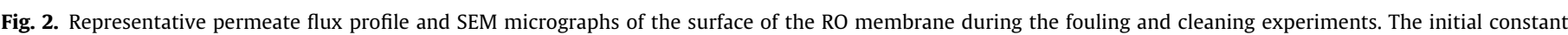

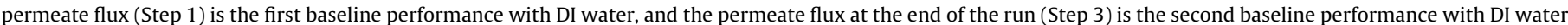

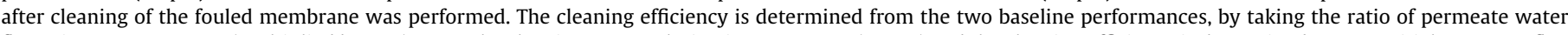

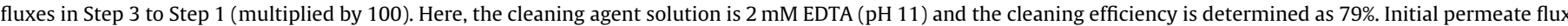

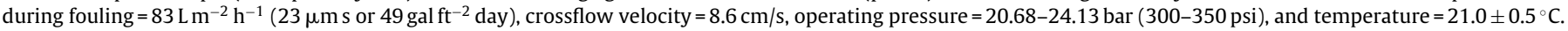

flux at the beginning of the experiment. The SEM image of the cleaned membrane indicates a significant reduction in the amount of foulant deposited on the membrane surface, compared to the fouled membrane.

\subsection{Membrane cleaning efficiency}

To look into the optimization of cleaning by cleaning agents, the effects of single, dual, and combined chemical cleaning on membranes fouled with wastewater effluent were investigated. The cleaning agents used were $\mathrm{NaOH}(\mathrm{pH} 11), 500 \mathrm{mM} \mathrm{NaCl}, 2 \mathrm{mM}$ EDTA, and $10 \mathrm{mM}$ SDS. $\mathrm{NaCl}$ has been proven to be effective in cleaning RO membranes fouled with hydrophilic organic matter such as alginate [15], while EDTA and SDS have been used more extensively in our research and proven to be effective in cleaning alginate-fouled membranes [24] and membranes fouled by mixtures of various organic foulants [11].

Fig. 3 presents a summary of the cleaning efficiencies measured in this study for all the agent combinations. Similar results, within experimental variation, were found for duplicate experiments carried out for selected fouling and cleaning runs (data not shown), indicating reproducibility of the data. Columns and rows refer to the first and second cleaning agent, respectively, used in dual-stage cleaning experiments of $7.5 \mathrm{~min}$ each. The shaded cells refer to one cleaning agent used for both steps, i.e., a single-stage cleaning experiment lasting $15 \mathrm{~min}$. The cleaning efficiency of combined cleaning agents is reported in brackets. The last row represents the cleaning efficiency of single-stage cleanings carried out for $7.5 \mathrm{~min}$.

Membrane fouling was largely irreversible, as cleaning the fouled membrane with DI water resulted in $32 \%$ cleaning efficiency. The cleaning efficiencies of $\mathrm{NaOH}(\mathrm{pH} \mathrm{11}), 500 \mathrm{mM} \mathrm{NaCl}$ (unadjusted pH 6.4), $10 \mathrm{mM}$ SDS (pH 7), and $2.0 \mathrm{mM}$ EDTA (pH 7), were, respectively, $59,65,77$, and $82 \%$ (shaded cells). In all cases, the cleaning efficiency of single agents was higher when cleaning time was increased from 7.5 (last row) to 15 min (shaded cells).
By comparing the cleaning efficiency of DI water on the membranes fouled by wastewater effluent (32\%) with that of the membranes fouled by combined model organic foulants in previous studies (19\%) [11], we can conclude that fouling by wastewater effluent has a larger potential for reversible fouling. On the other hand, the various cleaning agents had lower cleaning efficiencies on membranes fouled by wastewater effluent. This observation suggests that the foulants within the irreversible fouling layer on membrane surfaces fouled by wastewater effluent have higher intermolecular adhesion force among themselves, as compared to the foulants on membrane surfaces fouled by synthetic organic foulants [11].

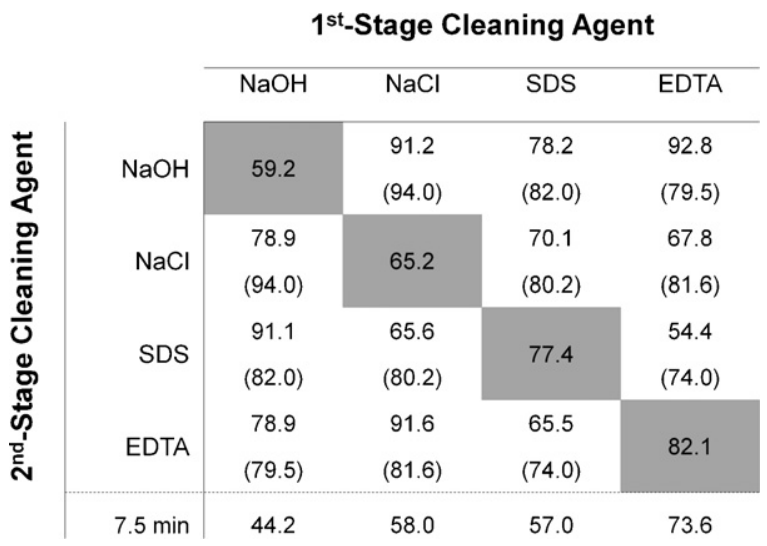

Fig. 3. Efficiencies of chemical cleaning. The columns denote the cleaning agent employed in the first-stage, while the rows represent the cleaning agent used in the second-stage. The efficiencies of single-stage cleaning (i.e., the same chemical throughout the cleaning) are indicated by the shaded cells. The efficiencies of a single-stage cleaning using a mixture of two chemical agents are shown in parenthesis below the cleaning efficiency. All cleaning strategies, except for the last row were performed for $15 \mathrm{~min}$ ( $7.5 \mathrm{~min}$ each for the $1 \mathrm{st}$-stage and 2 nd-stage). The last row represents the cleaning efficiency of a single-stage cleaning for $7.5 \mathrm{~min}$. 
In the following sections, results obtained using single agents will be compared to dual-stage cleaning experiments and significant trends will be highlighted. Practical insight can be gained by identifying the most functional combinations of cleaning agents, and drawing a connection to the cleaning mechanism of each respective agent. We note that in industrial spiral wound modules the use of spacers can enhance the mixing at the membrane-feed boundary layer, and thus increase the magnitude of the chemical cleaning efficiency of fouled membranes compared to our experiments $[28,29]$. Nonetheless, the general trends of cleaning efficiency discussed in this study are expected to be applicable to such spiral wound modules and other similar membrane systems. This knowledge can help to instruct efforts to maximize cleaning efficiency and, in turn, restore higher membrane water productivity.

\subsection{Influence of alkaline solution on efficiency of dual-step cleaning}

In our study, cleaning efficiencies were usually enhanced when the solution $\mathrm{pH}$ was increased during the first stage of a dualstage cleaning experiment, or when $\mathrm{NaOH}$ was used in combination with other cleaning agents, compared to the respective single-stage cleaning protocols (Fig. 3). This observation is consistent with the findings reported in other studies [30-32]. At pH 11, most of the functional groups present in the wastewater effluent are deprotonated (Fig. 1) and, therefore, the foulants are negatively charged. Under these conditions, the repulsive interactions among the constituents of the fouling layer were previously observed to facilitate the release of the layer and the transport of foulants from the membrane surface to the bulk solution [11,24]. As NaOH removes foulant on the membrane surface by hydrolysis and solubilization, the fouling layer matrix becomes more porous and facilitates the transfer of other cleaning agents into the fouling layer matrix [11].

This synergy was apparent for the cleaning experiments using $\mathrm{NaOH}$ in conjunction with $\mathrm{NaCl}$. Fig. 4A presents the cleaning efficiencies of $\mathrm{NaOH}$ and $\mathrm{NaCl}$ for different cleaning orders and combinations on membranes fouled by wastewater effluent. By cleaning with $\mathrm{NaOH}$ followed by $\mathrm{NaCl}(\mathrm{NaOH} \rightarrow \mathrm{NaCl})$ and, especially, by using a combination of the two agents $(\mathrm{NaOH}+\mathrm{NaCl}$, i.e., $\mathrm{NaCl}$ at $\mathrm{pH} 11$ ), the transfer of $\mathrm{NaCl}$ from the bulk solution to the fouling layer was facilitated. The resultant cleaning efficiencies were significantly higher than cleaning efficiencies of $\mathrm{NaOH}$ or $\mathrm{NaCl}$ used as single cleaning agents for the same duration of $15 \mathrm{~min}$.

The same synergistic effect was observed when $\mathrm{NaOH}$ was used in combination with SDS (Fig. 4B). The cleaning mechanism of SDS involves the formation of SDS micelles around the foulant and subsequent transport of the foulant from the membrane surface to the bulk solution $[24,30]$. SDS molecules do not interact specifically with $\mathrm{Ca}^{2+}$ in the polysaccharide-calcium complex. Thus, SDS molecules are expected to have more difficulty in breaking down the structural integrity of the fouling layer matrix and removing the foulant when the SDS is added first as opposed to when it is added as a succeeding cleaning agent after $\mathrm{NaOH}$. Our experiments confirmed that addition of $\mathrm{NaOH}$ as a preceding or combined cleaning agent helped to achieve higher cleaning efficiencies than those obtained by using SDS alone. $\mathrm{NaOH}$ facilitated SDS in breaking up the fouling layer matrix, forming micelles around the foulant, and transporting the foulants from the membrane surface to the bulk solution.

\subsection{Comparing single- and dual-step cleaning at ambient $\mathrm{pH}$}

Combining two different cleaning agents was not necessarily advantageous, in particular when the cleaning mechanisms of the two agents were such that the agents could not intensify each other.
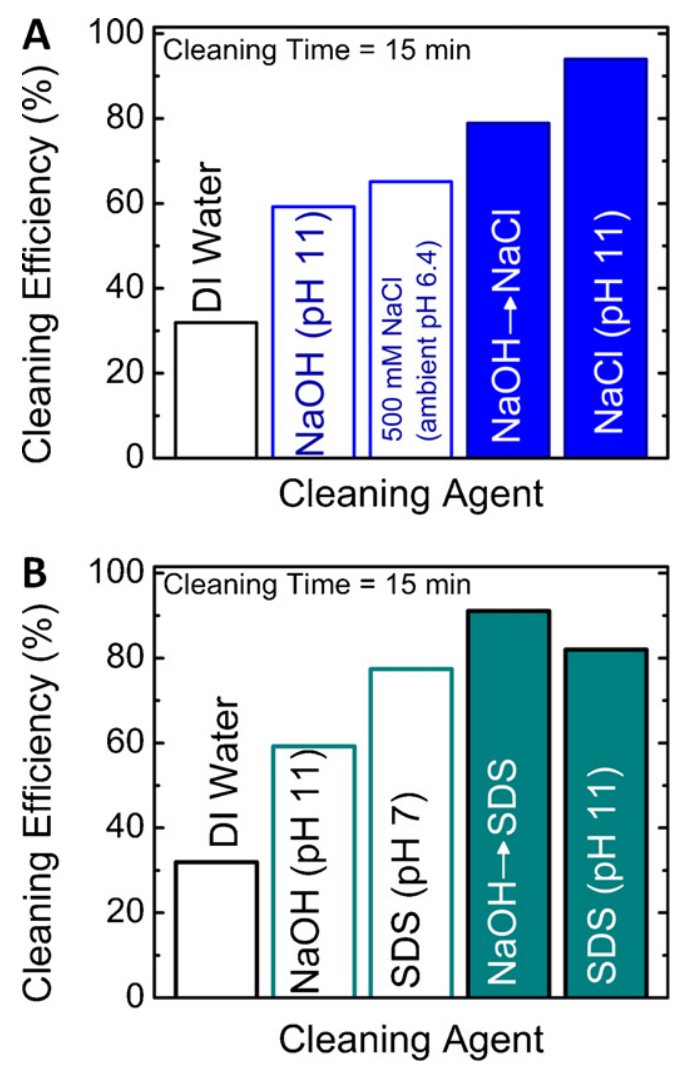

Fig. 4. Cleaning efficiencies of (A) $\mathrm{NaOH}$ and $\mathrm{NaCl}$ and (B) $\mathrm{NaOH}$ and SDS on membranes fouled by wastewater effluent, as single-step cleaning, dual-step cleaning, and combination of usage. Cleaning efficiency of DI water is also reported. Cleaning was performed at $0 \mathrm{psi}$ (no permeation) and at a cross-flow velocity of $42.8 \mathrm{~cm} / \mathrm{s}$ ( 5 times the velocity employed during fouling experiments). The temperature during cleaning was maintained at $21.0 \pm 0.5^{\circ} \mathrm{C}$.

Fig. 5 shows the efficiencies of EDTA and SDS for different cleaning orders and combinations on membranes fouled by wastewater effluent. No combination of the two agents resulted in cleaning efficiencies as high as using single-stage, 15 -min cleaning protocols. It is hypothesized that having one of the two agents adsorbed onto the fouling layer after the first cleaning stage hinders the cleaning process of the agent used in the second stage. Also, the simultaneous presence of both SDS and EDTA in the cleaning mixture negatively impacted the efficiency of each respective agent.

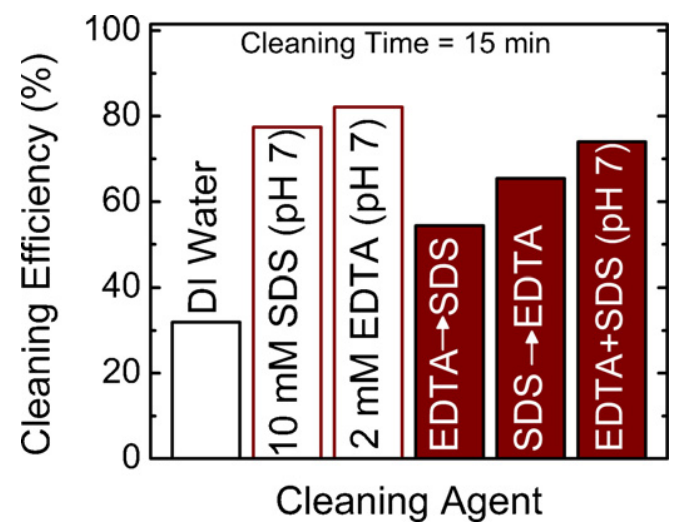

Fig. 5. Cleaning efficiencies of SDS and EDTA on membranes fouled by wastewater effluent as single-step cleaning, dual-step cleaning, and combination of usage Cleaning efficiency of DI water is also reported. Cleaning was performed at 0 psi (no permeation), and the cross-flow velocity was $42.8 \mathrm{~cm} / \mathrm{s}$ ( 5 times the velocity employed during fouling experiments). The temperature during cleaning was maintained at $21.0 \pm 0.5^{\circ} \mathrm{C}$. 


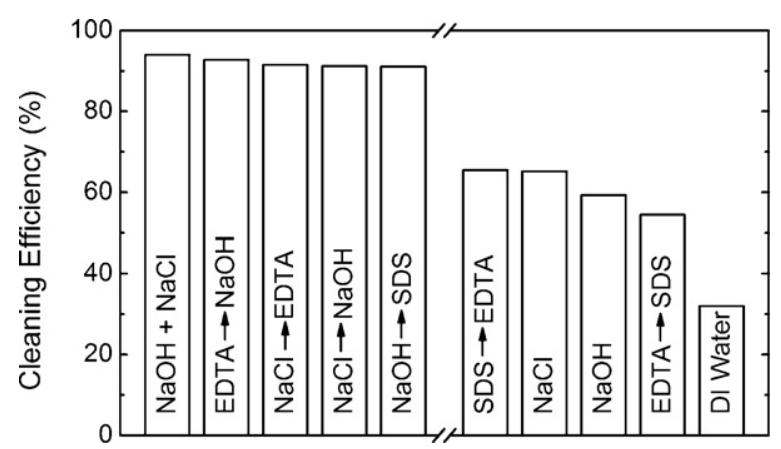

Fig. 6. Cleaning efficiencies of the top and bottom five performing strategies. All cleaning runs were performed for $15 \mathrm{~min}$ at $0 \mathrm{psi}$ (no permeation) and at a cross-flow velocity of $42.8 \mathrm{~cm} / \mathrm{s}$ ( 5 times the velocity employed during fouling experiments). The temperature during cleaning was maintained at $21.0 \pm 0.5^{\circ} \mathrm{C}$.

Another example showing higher efficacy of individual agents compared to their use in dual-stage cleaning protocols occurred with $\mathrm{NaCl}$ and SDS. Cleaning with $\mathrm{NaCl}$ followed by SDS yielded only a small increase in cleaning efficiency (65.6\%) compared to single, $7.5-\mathrm{min}$ (58.0\%) and 15-min (65.2\%) cleaning experiments with $\mathrm{NaCl}$. When the cleaning agents were added in the opposite order $(\mathrm{SDS} \rightarrow \mathrm{NaCl}$ ), a higher cleaning efficiency was observed $(70.1 \%)$ although it was still lower than that observed when using only SDS for $15 \mathrm{~min}$ (77.4\%). These experiments suggest that combining cleaning agents is only beneficial if their cleaning mechanisms are mutually compatible. On the other hand, cleaning hindrance can occur between different agents if the respective cleaning mechanisms interfere with each other.

\subsection{Combined chemical agents yield high cleaning efficiency}

The cleaning efficiencies of all strategies investigated in this study are summarized in Fig. 3. To compare the most and least effective methods, the five highest and five lowest cleaning efficiencies among the 15-min cleaning experiments were identified and presented in Fig. 6 in decreasing order of cleaning efficiency. The highest cleaning efficiency (94.0\%) for the RO membrane fouled by wastewater effluent was achieved using a $500 \mathrm{mM} \mathrm{NaCl}$ solution adjusted to $\mathrm{pH} 11.0$. On their own, $\mathrm{NaOH}$ and $\mathrm{NaCl}$ had the third and fourth lowest cleaning efficiency, respectively. Furthermore, when we look at the top five strategies, all of them involved dual or combined cleaning agents. Both of these findings indicate that, by strategically pairing two cleaning chemicals in dual or combined application, higher cleaning performance can be achieved when compared to the use of individual cleaning agents.

The emphasis here is on the appropriate pairing of chemicals such that their cleaning mechanisms complement each other. For example, the occurrence of $\mathrm{NaOH}$ in four of the five most effective strategies is a testament to the synergistic effect of elevated alkalinity on improving cleaning efficiency, as discussed earlier in Section 3.4. On the other hand, the mismatching of chemical agents, such as the pairing of EDTA with SDS (as discussed in Section 3.5 and illustrated in Fig. 5), would yield the opposite effect, resulting in a drastic decrease in cleaning performance.

\section{Conclusion}

This study presents the findings on the efficiency of various chemical cleaning strategies for an RO membrane fouled by a wastewater effluent. The use of single and paired chemicals and chemical combinations from four categories of cleaning agents that included alkaline solutions, metal chelating agents, surfactants, and salt solutions was investigated. The results indicate that by strategically pairing chemical agents that have complementary cleaning mechanisms, a higher cleaning efficiency can be attained. In particular, $\mathrm{NaOH}$ demonstrates exceptional capacity to enhance overall cleaning performance when introduced with other chemical agents, possibly due to its ability to loosen the fouling layer. These conclusions have significant implications for mitigating fouling of RO membranes in wastewater reuse applications. Pairing of cleaning agents not covered in this study, such as acid rinsing [18], could potentially produce similar synergistic effects and yield even higher cleaning efficiencies. Prudent cleaning strategies, where two or more chemical agents are employed in sequence or in combination, can be formulated to achieve optimal performance recovery while minimizing overall chemical consumption.

\section{Acknowledgments}

This study was funded by the U.S. Department of the Interior, Bureau of Reclamation, Desalination and Water Purification Research and Development Program (Award No. 05-FC-81-1147) and by the Public Utilities Board (PUB) of Singapore through a doctoral fellowship to W.S. Ang. We also acknowledge the Graduate Fellowship made by the Environment and Water Industrial Development Council of Singapore to Ngai Yin Yip and the NWRI-AMTA Fellowship for membrane technology to Alberto Tiraferri. The LFC-1 membranes were provided by Hydranautics.

\section{References}

[1] D. Barker, S. Salvi, A. Langenhoff, D. Stuckey, Soluble microbial products in ABR treating low-strength wastewater, Journal of Environmental Engineering-ASCE 126 (2000) 239-249.

[2] S. Lee, W.S. Ang, M. Elimelech, Fouling of reverse osmosis membranes by hydrophilic organic matter: implications for water reuse, Desalination 187 (2006) 313-321.

[3] S. Hong, M. Elimelech, Chemical and physical aspects of natural organic matter (NOM) fouling of nanofiltration membranes, Journal of Membrane Science 132 (1997) 159-181.

[4] C.R. Bartels, M. Wilf, K. Andes, J. Iong, Design considerations for wastewater treatment by reverse osmosis, Water Science and Technology 51 (2005) $473-482$

[5] S. Ebrahim, Cleaning and regeneration of membranes in desalination and waste-water applications-state-of-the-art, Desalination 96 (1994) 225-238.

[6] R. Liikanen, J. Yli-Kuivila, R. Laukkanen, Efficiency of various chemical cleanings for nanofiltration membrane fouled by conventionally-treated surface water, Journal of Membrane Science 195 (2002) 265-276.

[7] S.S. Madaeni, T. Mohamamdi, M.K. Moghadam, Chemical cleaning of reverse osmosis membranes, Desalination 134 (2001) 77-82.

[8] T. Mohammadi, S.S. Madaeni, M.K. Moghadam, Investigation of membrane fouling, Desalination 153 (2003) 155-160.

[9] D.Q. Ren, Cleaning and regeneration of membranes, Desalination 62 (1987) 363-371.

[10] J.J. Sadhwani, J.M. Veza, Cleaning tests for seawater reverse osmosis membranes, Desalination 139 (2001) 177-182.

[11] W.S. Ang, A. Tiraferri, K.L. Chen, M. Elimelech, Fouling and cleaning of RO membranes fouled by mixtures of organic foulants simulating wastewater effluent, Journal of Membrane Science 376 (2011) 196-206.

[12] G. Tragardh, Membrane cleaning, Desalination 71 (1989) 325-335.

[13] N.M. D'Souza, A.J. Mawson, Membrane cleaning in the dairy industry: a review, Critical Reviews in Food Science and Nutrition 45 (2005) 125-134.

[14] M. Rosen, Surfactant and Interfacial Phenomena, 2nd ed., Wiley, New York, 1989.

[15] S. Lee, M. Elimelech, Salt cleaning of organic-fouled reverse osmosis membranes, Water Research 41 (2007) 1134-1142.

[16] A.M. Klupfel, F.H. Frimmel, Nanofiltration of river water-fouling, cleaning and micropollutant rejection, Desalination 250 (2010) 1005-1007.

[17] P. Pihko, T. Rissa, R. Aksela, Enantiospecific synthesis of isomers of AES, a new environmentally friendly chelating agent, Tetrahedron 60 (2004) 10949-10954.

[18] S.S. Madaeni, S. Samieirad, Chemical cleaning of reverse osmosis membrane fouled by wastewater, Desalination 257 (2010) 80-86.

[19] M. Dubois, K. Gilles, J. Hamilton, P. Rebers, F. Smith, Colorimetric method for determination of sugars and related substances, Analytical Chemistry 28 (1956) 350-356.

[20] P.C.C.T. Bulletin, Instructions for Modified Lowry Protein Assay Kit in, Pierce Biotechnology Inc., 2005.

[21] G. Wang, S. Hsieh, Monitoring natural organic matter in water with scanning spectrophotometer, Environment International 26 (2001) 205-212. 
[22] B. Brugger, G. Erben, R. Sandhoff, F.T. Wieland, W.D. Lehmann, Quantitative analysis of biological membrane lipids at the low picomole level by nano-electrospray ionization tandem mass spectrometry, Proceedings of the National Academy of Sciences of the United States of America 94 (1997) 2339-2344.

[23] W.S. Ang, M. Elimelech, Fatty acid fouling of reverse osmosis membranes: implications for wastewater reclamation, Water Research 42 (2008) 4393-4403.

[24] W.S. Ang, S.Y. Lee, M. Elimelech, Chemical and physical aspects of cleaning of organic-fouled reverse osmosis membranes, Journal of Membrane Science 272 (2006) 198-210.

[25] E. Vrijenhoek, S. Hong, M. Elimelech, Influence of membrane surface properties on initial rate of colloidal fouling of reverse osmosis and nanofiltration membranes, Journal of Membrane Science 188 (2001) 115-128.

[26] C. Tang, Y. Kwon, J. Leckie, Probing the nano- and micro-scales of reverse osmosis membranes-a comprehensive characterization of physiochemical properties of uncoated and coated membranes by XPS, TEM, ATR-FTIR, and streaming potential measurements, Journal of Membrane Science 287 (2007) 146-156.
[27] M. Collins, G. Amy, C. Steelink, Molecular weight distribution, carboxylic acidity, and humic substances content of aquatic organic matter: implications for removal during water treatment, Environmental Science \& Technology 20 (1986) 1028-1032.

[28] M.L. Johns, S.A. Creber, J.S. Vrouwenvelder, M.C.M. van Loosdrecht, Chemical cleaning of biofouling in reverse osmosis membranes evaluated using magnetic resonance imaging, Journal of Membrane Science 362 (2010) 202-210.

[29] J.S. Vrouwenvelder, D.A.G. von der Schulenburg, J.C. Kruithof, M.L. Johns, M.C.M. van Loosdrecht, Biofouling of spiral-wound nanofiltration and reverse osmosis membranes: a feed spacer problem, Water Research 43 (2009) 583-594.

[30] Q.L. Li, M. Elimelech, Organic fouling and chemical cleaning of nanofiltration membranes: measurements and mechanisms, Environmental Science \& Technology 38 (2004) 4683-4693.

[31] M. Beyer, B. Lohrengel, L.D. Nghiem, Membrane fouling and chemical cleaning in water recycling applications, Desalination 250 (2010) 977-981.

[32] Y.H. Mo, J.H. Chen, W.C. Xue, X. Huang, Chemical cleaning of nanofiltration membrane filtrating the effluent from a membrane bioreactor, Separation and Purification Technology 75 (2010) 407-414. 